\title{
HelloCare: APLIKASI MANAJEMEN PENGETAHUAN BERBASIS ANDROID UNTUK TENAGA KESEHATAN
}

\author{
${ }^{1}$ Herika Hayurani, ${ }^{2}$ Hamnah, ${ }^{3}$ Ummi Azizah Rachmawati, ${ }^{4}$ Elan Suherlan \\ 1,2,3,4 Program Studi Teknik Informatika, Fakultas Teknologi Informasi, Universitas YARSI, \\ Jakarta, Indonesia \\ E-mail: herika.hayurani@gmail.com
}

\begin{abstract}
Technology Development in the health sector is one of the main targets in mobile application development today. Sharing knowledge and experience among health workers are challenging to implement because of the lack of a place to exchange their ideas. Based on this background, we built a HelloCare application on the Android platform as an application of knowledge management for health workers. Testing of the application using the System Usability Scale (SUS) to 30 respondents consisting of nurses and physicians, the result of effectiveness is $80.88 \%$ as for satisfaction is $96.16 \%$. We also test the application using knowledge management functions and get the average result at score 3.33871 of 5. It means that the HelloCare application is good enough to support knowledge management in the health area.
\end{abstract}

Keywords: knowledge management, mobile application, health workers

\begin{abstract}
Abstrak
Perkembangan teknologi di bidang kesehatan menjadi sasaran utama dalam pembuatan aplikasi mobile. Berbagi ilmu serta pengalaman antar sesama tenaga kesehatan sulit diterapkan karena minimnya wadah untuk bertukar pikiran. Namun, aplikasi HelloCare akan menjadi sarana bagi tenaga kesehatan agar tetap terus bisa mengamalkan ilmunya serta membuat mereka bisa terus berkarya. Berdasarkan latar belakang tersebut maka dibangun sebuah aplikasi HelloCare, yaitu sebuah aplikasi manajemen pengetahuan untuk para tenaga kesehatan. Dalam pengujian dilakukan dengan metode System Usability Scale (SUS). Dari hasil pengujian SUS sistem ini dinyatakan memiliki usability yang baik dengan persentase efektifitas $80,88 \%$ dan uji kepuasan sebanyak $96,16 \%$ dari 30 responden yang terdiri dari perawat dan dokter. Kemudian dengan menggunakan pengujian penerapan fungsi-fungsi knowledge management, rata-rata yang dihasilkan sebesar 3,33871 dari 5. Keberhasilan mencapai nilai menengah, secara fungsional aplikasi HelloCare cukup baik dalam pemanfaatannya pada penerapan knowledge management di bidang kesehatan.
\end{abstract}

Kata Kunci: sistem manajemen pengetahuan, aplikasi mobile, tenaga kesehatan 


\section{Pendahuluan}

Saat ini kita berada pada era dimana teknologi menjadi peran penting dalam membantu segala kebutuhan hidup sehari-hari. Teknologi mampu berkembang di berbagai lingkup kehidupan, mulai dari bidang teknologi itu sendiri, bidang ekonomi, kesehatan dan lain sebagainya. Teknologi berkontribusi untuk mempermudah segala bentuk kegiatan yang dilakukan oleh manusia menjadi lebih mudah. Perkembangan teknologi yang cukup pesat ini diharapkan dapat melayani segala kebutuhan manusia dengan cepat. Salah satu peranan teknologi yang paling dibutuhkan adalah dalam menggali ilmu, informasi, serta pengetahuan. Kebanyakan situs yang kita kunjungi saat ini mencakup wawasan, ilmu, atau pengetahuan yang bisa didapatkan. Beberapa peranan teknologi yang bergerak dalam hal berbagi ilmu adalah dengan adanya bentuk media sosial yang digunakan untuk bertukar informasi serta penggunaan e-learning dalam hal perkuliahan. Bentuk pelayanan berbagi ilmu tersebut akan mendapatkan respon cepat sesuai kebutuhan yang ingin didapatkan.

Saat ini bentuk pengkajian terhadap knowledge management sudah banyak dilakukan untuk bisa diterapkan terhadap organisasiorganisasi di berbagai bidang. Knowledge management merupakan satu hal yang sangat diperlukan untuk mencapai tujuan organisasi yang lebih baik melalui strategi yang didorong oleh motivasi dan fasilitas knowledge pekerja yang bisa mengembangkan, meningkatkan, dan menggunakan kemampuan untuk menafsirkan suatu sumber data dan informasi (Moteleb dan Woodman, 2007).

Mengelola knowledge berarti mendayagunakan knowledge yang ada, baik memanfaatkan knowledge dari masing-masing individu maupun dari hasil diskusi sebuah kelompok yang digunakan untuk kebutuhan proses pengetahuan bagi tenaga kesehatan. Pengelolaan knowledge tersebut dimodelkan dalam suatu sistem yang disebut Knowledge Management System. Knowledge Management System dapat ditingkatkan dengan model yang efektif dan efisien. Dikatakan model yang efektif dan efisien karena model ini memberikan pengelolaan knowledge yang tak terbatas kepada penggunanya.

Paparan di atas merupakan ide dasar mengapa dibutuhkan Knowledge Management System (Sistem Manajemen Pengetahuan) yang diutamakan untuk tenaga kesehatan. Knowledge Management System tersebut berisi knowledge yang nantinya sangat dibutuhkan bagi siapapun yang berada di bidang kesehatan, dimana manfaat dari pembuatan Knowledge Management System ini adalah sebagai sarana penyedia sumber pengetahuan dengan struktur yang baik, yang nantinya akan memudahkan para tenaga kesehatan dalam hal memperoleh pengetahuan yang lebih cepat sehingga dapat meminimalisir waktu. Peningkatan aset pengetahuan dapat dimanfaatkan para tenaga kesehatan dalam memperoleh sumber pengetahuan serta dapat dijadikan sarana untuk membangun budaya berbagi ilmu antar sesama tenaga kesehatan.

Oleh karena itu tenaga kesehatan membutuhkan sarana pembelajaran untuk melakukan transfer dan sharing knowledge demi mendukung kinerja tenaga kesehatan di seluruh Indonesia. Knowledge sharing merupakan salah satu proses dari Knowledge management. Dimana kegiatan knowledge sharing di bidang kesehatan terutama bagi para tenaga kesehatan, secara keseluruhan mereka melakukan komunikasi dan saling bertukar ilmu pengetahuan yang mereka kuasai selama ini.

Penggunaan smartphone android kini menjadi pilihan yang tepat bagi masyarakat Indonesia. Penggunaannya yang user friendly, harganya yang terjangkau dan berbagai tipenya yang mudah didapatkan, android menjadi salah satu sistem operasi yang banyak dicari. Pada pertengahan tahun 2016, pengguna android di Indonesia mencapai $77 \%$. Dengan persaingan sistem operasi seperti iOS, Blackberry, Nokia, dan beberapa lainnya yang berada di posisi di bawah dari sistem operasi android (StatCounter, Januari 2016).

\subsection{Knowledge Management}

Knowledge management yaitu proses yang berkelanjutan, mencari nilai dan menggunakannya untuk informasi yang masih belum dikelola dan dibagi ke seluruh batas-batas organisasi (Bonner, 2000). "Knowledge management adalah proses formal, mengarah pada proses menentukan informasi apa yang dimiliki perusahaan yang bisa menguntungkan orang lain dalam perusahaan dan kemudian merencanakan bagaimana cara untuk membuatnya mudah didapatkan" (Liss, 1999, hal. 1). Sedangkan Groff dan Jones (2003:2) mengatakan "knowledge management is taken as tools, techniques and strategies to retai, analize, organize, improve and share business expertise." Manajemen pengetahuan adalah alat, teknik, strategi untuk menyimpan, menganilisis, mengorganisir, meningkatkan dan membagikan pengalaman

bisnis. 
Definisi yang lain menyebutkan, "Knowledge management is the formalization of and access to experience, knowledge and expertise that create new capabilities, enable superior performance, encourage innovation and enhance customer value" (Beckman, 1997 dalam Liebowitz 1999). Dalam pandangan ini manajemen pengetahuan adalah formalisasi akses pengalaman, pengetahuan yang dapat menciptakan kapabilitas baru, kinerja yang superior, meningkatkan inovasi dam nilai pelanggan. Dan Macintosh dalam Halawi et all (1996) menyatakan "knowledge management involve the identification and alysis of available and require knowledge and the subsequence planning and control of actions to develop knowledge assets so as to fulfil organization objectives $\hat{\imath}$ '. Manajemen pengetahuan melibatkan identifikasi dan analisis pengetahuan yang tersedia dan dibutuhkan yang digunakan untuk perencanaan dan pengawasan tindakan untuk meningkatkan kekayaan intelektual guna mencapai tujuan organisasi.

Mengingat literatur yang terdapat pada (Grover dan Davenport, 2001; Nonaka, 1991), knowledge management dapat direpresentasikan secara generik menjadi empat aktivitas cyclic: knowledge creation, knowledge codification, knowledge transfer, and knowledge application. Siklus knowledge management ditunjukkan pada Gambar 1.

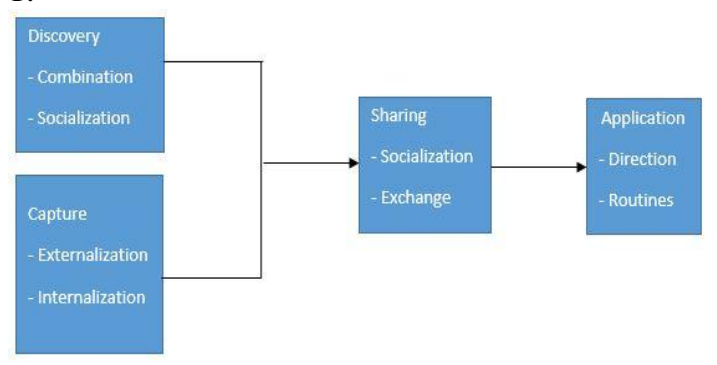

Gambar 1. Proses knowledge management (Becerra Fernandez \& Sabherwal, 2010)

Masing-masing proses dari knowledge management tersebut dijelaskan dalam poin-poin berikut:

1. Knowledge discovery

Knowledge discovery merupakan pengembangan explicit dan tacit knowledge dari data atau informasi, maupun dari sintesa pengetahuan sebelumnya (Becerra Fernandez dan Sabherwal, 2010). Contoh combination adalah mempelajari bagaimana caranya menggunakan aplikasi mobile HelloCare dan contoh socialization adalah terdapat suatu kumpulan pengguna aplikasi HelloCare dan membicarakan mengenai perkembangan yang lebih baik dalam pembuatan aplikasi tersebut (Tiwana, 2003).

\section{Knowledge capture}

Knowledge capture merupakan proses pemanggilan explicit dan tacit knowledge yang berada pada orang, artefak atau entitas organisasi (Becerra Fernandez \& Sabherwal, 2010). Contoh dari externalization adalah seorang dokter yang menjelaskan bagaimana suatu masalah dipecahkan dan contoh internalization adalah mempelajari suatu bahan pada forum diskusi (Tiwana, 2003).

3. Knowledge sharing

Knowledge sharing merupakan proses mengkomunikasikan explicit dan tacit knowledge terhadap antara satu individu dengan individu lainnya (Becerra Fernandez dan Sabherwal, 2010). Penerapan yang dilakukan oleh penulis terhadap aplikasi yang dibuat adalah dengan adanya fitur forum diskusi, tujuannya adalah agar user dapat berkomunikasi satu sama lain layaknya dalam suatu grup. Selain itu sharing bisa memanfaatkan bahan-bahan seperti file yang dibagikan atau gambar yang dilampirkan.

4. Knowledge application

Knowledge application merupakan suatu pengaplikasian knowledge yang tergantung dari ketersediaan knowledge, proses dari knowledge discovery, capture, dan sharing. Contoh direction adalah dalam sebuah forum terdapat seseorang yang mengajukan statement atau bertanya pada grup (dimana terdapat kemungkinan jawaban benar atau salah). Selanjutnya, contoh dari routines adalah sistem enterprise yang dikodifikasi dengan routines, dimana hal tersebut mendeskripsikan proses bisnis dalam segmen industri (Becerra Fernandez dan Sabherwal, 2010).

\section{Metodologi}

Untuk dapat melaksanakan penelitian ini diperlukan tahapan-tahapan yang dapat memudahkan penulis untuk menyusun penelitiannya dengan baik, berikut ini tahapan yang dilakukan: 


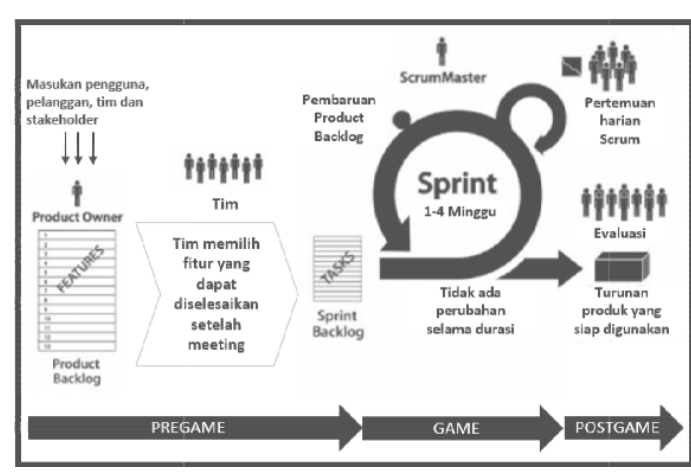

Gambar 2 Tahapan dan pihak yang terlibat dalam metode Scrum (Ken Schwaber, 2013)

Munculnya metode baru yang diperkenalkan oleh seorang ilmuwan baru di bidang teknologi kini mampu merubah berjalannya pengerjaan proyek pada suatu sistem. Membantu mengatasi permasalahan yang selama ini menggunakan metode yang telah diperkenalkan pada tahun 1990an dan metode pada masa kini mampu menangani permasalahan yang ada, metode tersebut dikenalkan dengan sebutan agile methods.

Arti kata agile sendiri berarti tangkas, cepat, atau ringan. Agility merupakan metode yang ringan dan cepat dalam pengembangan perangkat lunak (Widodo \& Subekti, 2006). Terdapat beberapa perbedaan yang dirasa saat menggunakan agile. Namun, pada akhirnya hal tersebut bisa didiskusikan berdasarkan kesepakatan tim. Secara umum tim proyek mengikuti life cycle yang sederhana, dimana mengulang setiap iterasi yang ada. Life cycle pada Gambar 3 fokus pada scrum. Scrum projects memiliki iterasi yang sangat sederhana (secara umum 1-3 minggu) yang disebut sebagai sprint. Berikut ini penjelasan mengenai tahapan pada Scrum.

\subsubsection{Scrum Master}

Scrum Master bertanggung jawab untuk memastikan fase metodologi Scrum dilakukan dengan baik. Scrum Master melindungi tim dan memastikan mereka tidak terlalu berkomitmen dengan apa yang mereka kerjakan, karena perubahan dapat terjadi pada tiap Sprint. Selain itu, Scrum Master juga memfasilitasi pertemuan harian dan bertanggung jawab untuk mengatasi hambatan yang terjadi. Peran Scrum Master biasanya diisi oleh seorang manajer proyek atau pemimpin tim teknis, namun bisa juga diisi oleh anggota tim yang lainnya (Ken Schwaber. 2013).

\subsubsection{Product Owner}

Product Owner yaitu salah satu dari tim yang menjadi juru kunci perihal pengetahuannya mengenai produk yang akan dikembangkan, memprioritaskan 'Product Backlog' (daftar yang sangat rinci mengenai hal-hal apa yang harus dilakukan dalam pengerjaan proyek). Tim Scrum mengurutkan Product Backlog berdasarkan prioritas dan berkomitmen untuk menyelesaikan semua hal yang sudah disepakati selama Sprint. Daftar ini nantinya akan disebut sebagai Sprint Backlog (Ken Schwaber. 2013).

\subsubsection{Project Backlog}

Di balik setiap proyek yang dilakukan oleh tim proyek adalah backlog proyek. Backlog proyek adalah sekumpulan daftar dari semua fitur produk pada umumnya yang telah ditentukan oleh "user stories". User stories menentukan segala potensi yang pengguna akan lakukan pada situs yang akan dibuat. Bahkan, salah satu cara terbaik untuk membuat inisial backlog proyek adalah menulis semua user stories pada post it notes selama kickoff meeting.

Setelah seluruh user stories diwujudkan, dilanjutkan dengan membuat rank berdasarkan urutan prioritas. Bagian dari peringkat ini juga mengelompokkan stories secara bersama-sama. Beberapa stories secara langsung akan melibatkan diri dari masing-masing tim yang tergabung untuk membangun proyek tertentu, yang nantinya akan mempercepat proses penyelesaian.

\subsubsection{Sprint Review}

Pada akhir setiap sprint terkadang mendapatkan nilai tertentu yang bisa diolah. Sesuatu yang secara teoritis telah diluapkan. Sprint review meeting secara bersama membawa tim proyek dan pemilik saham proyek yang lain seperti client untuk menyampaikan pekerjaan yang telah diselesaikan.

\subsection{Tahap Analisis}

Pada tahap analisis, penulis melakukan wawancara kepada product owner dan menghasilkan daftar fitur yang akan dikembangkan pada aplikasi HelloCare, yaitu: fitur update (posting), forum diskusi, fitur rating maximum, profil user. Selanjutnya penulis membuat bentuk pertanyaan yang dijadikan sebagai bahan acuan untuk diujikan kepada responden. Tabel 1, Tabel 2, Tabel 3, dan Tabel 4 merupakan tabel daftar pertanyaan yang terdiri dari dokter-dokter, perawat, serta mahasiswa yang bergerak dalam bidang kesehatan.

Berikutnya adalah Gambar 3 yang merupakan gambar dari tampilan login pada aplikasi HelloCare dimana pengguna dapat memasukkan email address dan password sesuai yang sudah didaftarkan pada fitur register. Setelah itu pengguna bisa masuk pada keseluruhan aplikasi HelloCare dengan cara memilih tombol login. Jika 
Jurnal Teknologi Informasi YARSI (JTIY), Vol. 6, No. 1, 2019, 25-34

pengguna lupa dengan password yang sudah didaftarkan pada form registrasi, maka terdapat fitur forgot password untuk mendapatkan password baru. 
Tabel 2. Pertanyaan manajemen pengetahuan

\begin{tabular}{|c|c|c|}
\hline Variabel & $\begin{array}{l}\text { Sub } \\
\text { Variable/Dimensi }\end{array}$ & Deskriptor \\
\hline \multirow[t]{9}{*}{$\begin{array}{l}\text { Knowledge } \\
\text { Discovery }\end{array}$} & $\begin{array}{l}\text { Mobile access for } \\
\text { data }\end{array}$ & $\begin{array}{l}\text { Layanan untuk mengakses suatu data yang terdapat dalam sebuah aplikasi } \\
\text { mobile. Contoh: fitur forum untuk upload foto atau file }\end{array}$ \\
\hline & $\begin{array}{l}\text { Repository of } \\
\text { information }\end{array}$ & $\begin{array}{l}\text { Tempat menyimpan data yang dikumpulkan dari berbagai sumber informasi, } \\
\text { sebagai sumber referensi bagi proses pembelajaran dan sebagai tempat } \\
\text { menyimpan pengetahuan yang dihasilkan pada proses pembelajaran (Batubara } \\
\text { 2012). Contoh: fitur Timeline. }\end{array}$ \\
\hline & $\begin{array}{l}\text { Lesson Learn } \\
\text { Database }\end{array}$ & $\begin{array}{l}\text { Kumpulan data yang disimpan secara sistematis di dalam smartphone dan dapat } \\
\text { diolah atau dimanipulasi menggunakan perangkat lunak untuk menghasilkan } \\
\text { informasi (Cahya 2015). Contoh: fitur mengakses file (pdf, word, excel) } \\
\text { menggunakan Microsoft. }\end{array}$ \\
\hline & Best Practice & $\begin{array}{l}\text { Implementasi suatu konsep/teknologi yang banyak dipakai oleh indvidual } \\
\text { maupun organisasi (Mardiansyah 2006). Contoh: update status pada fitur } \\
\text { timeline untuk berbagi pengalaman. }\end{array}$ \\
\hline & Lesson Learn & $\begin{array}{l}\text { Pengetahuan yang diperoleh melalui pengalaman jika dibagi dapat bermanfaat } \\
\text { bagi pihak lain (Yahyah 2010). Contoh: update status pada fitur timeline untuk } \\
\text { berbagi pengalaman }\end{array}$ \\
\hline & On Device Portal & $\begin{array}{l}\text { Sebuah aplikasi mobile yang menyediakan beragam informasi dari berbagai } \\
\text { sumber dengan cara (format/layout) yang seragam. Biasanya, setiap sumber } \\
\text { informasi mendapat area khusus pada screen untuk menampilkan informasi } \\
\text { (Sasongko 2011). Contoh: fitur Wiki }\end{array}$ \\
\hline & Data Mining & $\begin{array}{l}\text { Serangkaian proses untuk menggali nilai tambah dari suatu kumpulan data } \\
\text { berupa pengetahuan yang selama ini tidak diketahui secara manual (Saputra } \\
\text { 2003). Contoh: fitur Wiki }\end{array}$ \\
\hline & Chat Group & $\begin{array}{l}\text { Fitur yang memungkinkan untuk melakukan chatting dengan lebih dari } 1 \text { orang. } \\
\text { Contoh: diskusi dalam fitur forum }\end{array}$ \\
\hline & $\begin{array}{l}\text { Electronic } \\
\text { Discussion Grup }\end{array}$ & $\begin{array}{l}\text { Layanan diskusi elektronik yang memungkinkan untuk melakukan diskusi } \\
\text { kelompok untuk pengumpulan informasi. }\end{array}$ \\
\hline
\end{tabular}

Nomor

Tabel 1. Pertanyaan tentang Knowledge Capture

\begin{tabular}{|c|c|c|c|}
\hline Variabel & $\begin{array}{l}\text { Sub } \\
\text { Variable/Dimensi }\end{array}$ & Deskriptor & $\begin{array}{l}\text { Nomor } \\
\text { Item }\end{array}$ \\
\hline \multirow[t]{7}{*}{$\begin{array}{l}\text { Knowledge } \\
\text { Capture }\end{array}$} & $\begin{array}{l}\text { Lesson Learn } \\
\text { Database }\end{array}$ & $\begin{array}{l}\text { Kumpulan data berupa pengetahuan yang diperoleh melalui pengalaman yang } \\
\text { disimpan secara sistematis di dalam handphone dan diolah atau dimanipulasi } \\
\text { menggunakan perangkat lunak (program aplikasi) untuk menghasilkan informasi. } \\
\text { Contoh: fitur mengakses file (pdf, word, excel) menggunakan Microsoft. }\end{array}$ & $\mathrm{KC} 1$ \\
\hline & $\begin{array}{l}\text { Lesson Learn } \\
\text { Model }\end{array}$ & $\begin{array}{l}\text { Model pengetahuan yang diperoleh melalui pengalaman. Contoh: update status } \\
\text { pada fitur timeline untuk berbagi pengalaman. }\end{array}$ & $\mathrm{KC} 2$ \\
\hline & $\begin{array}{l}\text { Manual Or } \\
\text { Reference Tutorial } \\
\text { For Best Practice } \\
\text { Model }\end{array}$ & Panduan atau referensi tutorial untuk best practice model. Contoh: fitur forum & $\mathrm{KC} 4$ \\
\hline & $\begin{array}{l}\text { AI Based } \\
\text { Experience }\end{array}$ & $\begin{array}{l}\text { Sistem kecerdasan buatan berdasarkan pengalaman. Contoh: update status pada } \\
\text { fitur timeline untuk berbagi pengalaman. }\end{array}$ & KC6 \\
\hline & $\begin{array}{l}\text { AI Based } \\
\text { Knowledge } \\
\text { Acquisition }\end{array}$ & Sistem kecerdasan buatan berdasarkan knowledge base. Contoh: fitur Wiki & $\mathrm{KC} 7$ \\
\hline & $\begin{array}{l}\text { Computer Based } \\
\text { Simulation }\end{array}$ & $\begin{array}{l}\text { Simulasi berbasis mobile melalui penciptaan tiruan-tiruan bentuk pengalaman. } \\
\text { Contoh: fitur daily reminder. }\end{array}$ & $\mathrm{KC} 8$ \\
\hline & $\begin{array}{l}\text { Computer Based } \\
\text { Communication }\end{array}$ & $\begin{array}{l}\text { Sebuah aplikasi mobile yang digunakan untuk berkomunikasi. Contoh: fitur forum } \\
\text { untuk diskusi antar pengguna }\end{array}$ & KC9 \\
\hline
\end{tabular}


Jurnal Teknologi Informasi YARSI (JTIY), Vol. 6, No. 1, 2019, 25-34

Table 3. Pertanyaan tentang Knowledge Application

\begin{tabular}{|c|c|c|c|}
\hline Variabel & $\begin{array}{l}\text { Sub } \\
\text { Variable/Dimensi }\end{array}$ & Deskriptor & $\begin{array}{l}\text { Nomor } \\
\text { Item }\end{array}$ \\
\hline \multirow[t]{8}{*}{$\begin{array}{l}\text { Knowledge } \\
\text { Application }\end{array}$} & $\begin{array}{l}\text { Capture and } \\
\text { Transfer of Expert } \\
\text { Knowledge }\end{array}$ & $\begin{array}{l}\text { Sistem yang dapat menyimpan dan mentransfer pengetahuan dari seorang ahli. } \\
\text { Contoh: fitur Wiki }\end{array}$ & KA1 \\
\hline & $\begin{array}{l}\text { Case Based } \\
\text { Reasoning System }\end{array}$ & $\begin{array}{l}\text { Sistem yang menitikberatkan pemecahan masalah dengan didasarkan pada } \\
\text { knowledge dari kasus-kasus sebelumnya. Apabila ada kasus baru maka akan } \\
\text { disimpan pada basis pengetahuan sehingga sistem akan melakukan learning dan } \\
\text { knowledge yang dimiliki oleh sistem akan bertambah (Yulmaini 2012). Contoh: } \\
\text { fitur forum untuk berdiskusi antar pengguna. }\end{array}$ & $\mathrm{KA} 2$ \\
\hline & Help Desk & $\begin{array}{l}\text { Salah satu media untuk membantu menyelesaikan masalah (biasanya yang } \\
\text { berhubungan dengan handphone/mobile) (Helpdesksoftware.co.id 2013). } \\
\text { Contoh: fitur daily activities. }\end{array}$ & KA3 \\
\hline & $D S S$ & $\begin{array}{l}\text { Sistem informasi manajemen yang secara khusus dibuat untuk mendukung } \\
\text { perencana dan stakeholders dalam pengambilan keputusan (Cahyono 2014). } \\
\text { Contoh: fitur daily reminder. }\end{array}$ & KA4 \\
\hline & $\begin{array}{l}\text { Enterprise Resource } \\
\text { Planning System }\end{array}$ & $\begin{array}{l}\text { Sistem terintegrasi yang mempunyai tujuan merangkum bisnis proses yang ada } \\
\text { sehingga menjadi satu kolaborasi yang efisien dan efektif dan sistem tersebut di } \\
\text { dukung dengan teknologi informasi dan dapat menghasilkan informasi yang } \\
\text { menunjang perusahaan menjadi lebih kompetitif (Isnaen 2015). Contoh: fitur } \\
\text { daily activities dan daily reminder. }\end{array}$ & KA5 \\
\hline & Expert System & $\begin{array}{l}\text { Sebuah aplikasi mobile yang mengandung pengetahuan dari satu atau lebih } \\
\text { pakar manusia mengenai suatu bidang spesifik. Pengetahuan dari pakar di dalam } \\
\text { sistem ini digunakan sebagi dasar oleh sistem pakar untuk menjawab pertanyaan } \\
\text { (konsultasi) (Wikipedia n.d.). Contoh: fitur Wiki }\end{array}$ & KA6 \\
\hline & $\begin{array}{l}\text { Database } \\
\text { Information System }\end{array}$ & $\begin{array}{l}\text { Kumpulan data yang disimpan secara sistematis di dalam aplikasi mobile dan } \\
\text { dapat dijadikan sumber informasi (Cahya 2015). Contoh: fitur forum yang bisa } \\
\text { membagikan file dan gambar }\end{array}$ & KA7 \\
\hline & $\begin{array}{l}\text { Management } \\
\text { Information System }\end{array}$ & $\begin{array}{l}\text { Suatu aplikasi sistem informasi yang menyediakan laporan informasi terpadu } \\
\text { (Auguar 2014). Contoh: fitur daily activities }\end{array}$ & KA8 \\
\hline
\end{tabular}

Tabel 4. Pertanyaan tentang Knowledge Sharing

\begin{tabular}{|c|c|c|c|}
\hline Variabel & $\begin{array}{l}\text { Sub } \\
\text { Variable/Dimensi }\end{array}$ & Deskriptor & $\begin{array}{l}\text { Nomor } \\
\text { Item }\end{array}$ \\
\hline \multirow[t]{6}{*}{$\begin{array}{l}\text { Knowledge } \\
\text { Sharing }\end{array}$} & $\begin{array}{l}\text { Electronic Discussion } \\
\text { Group }\end{array}$ & $\begin{array}{l}\text { Layanan diskusi elektronik yang memungkinkan untuk melakukan diskusi } \\
\text { kelompok untuk pengumpulan berbagai informasi. Contoh: fitur forum }\end{array}$ & KS1 \\
\hline & $\begin{array}{l}\text { Application to } \\
\text { Database }\end{array}$ & $\begin{array}{l}\text { Layanan untuk mengakses suatu data yang terdapat dalam sebuah aplikasi. } \\
\text { Contoh: mengakses file (pdf, word, docx, dll) ke database. }\end{array}$ & KS2 \\
\hline & Lesson Learn System & $\begin{array}{l}\text { Pengetahuan yang diperoleh melalui pengalaman jika dibagi dapat bermanfaat } \\
\text { bagi pihak lain (Yahyah 2010). Contoh: update status pada fitur timeline untuk } \\
\text { berbagi pengalaman }\end{array}$ & KS3 \\
\hline & $\begin{array}{l}\text { Best Practice } \\
\text { Database }\end{array}$ & $\begin{array}{l}\text { Implementasi suatu konsep/teknologi yang banyak dipakai oleh indvidual } \\
\text { maupun organisasi (Mardiansyah 2006). Contoh: update status pada fitur } \\
\text { timeline untuk berbagi pengalaman. }\end{array}$ & KS4 \\
\hline & $\begin{array}{l}\text { Repository of } \\
\text { information }\end{array}$ & $\begin{array}{l}\text { Tempat menyimpan data yang dikumpulkan dari berbagai sumber informasi, } \\
\text { sebagai sumber referensi bagi proses pembelajaran dan sebagai tempat } \\
\text { menyimpan pengetahuan yang dihasilkan pada proses pembelajaran (Batubara } \\
\text { 2012). Contoh: fitur Timeline. }\end{array}$ & KS5 \\
\hline & $\begin{array}{l}\text { Team Collaboration } \\
\text { Tools }\end{array}$ & $\begin{array}{l}\text { Aplikasi yang memudahkan team dalam komunikasi, berbagi informasi, } \\
\text { sharing data dll. Contoh: fitur forum }\end{array}$ & KS6 \\
\hline
\end{tabular}




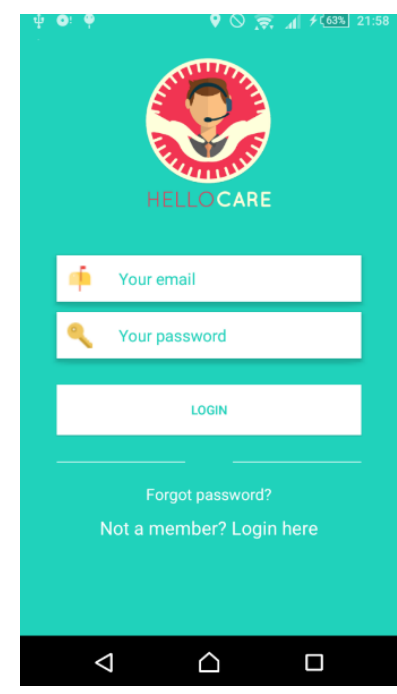

Gambar 3. Halaman login pada aplikasi HelloCare

Berikutnya adalah Gambar 3 yang merupakan gambar dari tampilan login pada aplikasi HelloCare dimana pengguna dapat memasukkan email address dan password sesuai yang sudah didaftarkan pada fitur register. Setelah itu pengguna bisa masuk pada keseluruhan aplikasi HelloCare dengan cara memilih tombol login. Jika pengguna lupa dengan password yang sudah didaftarkan pada form registrasi, maka terdapat fitur forgot password untuk mendapatkan password baru.

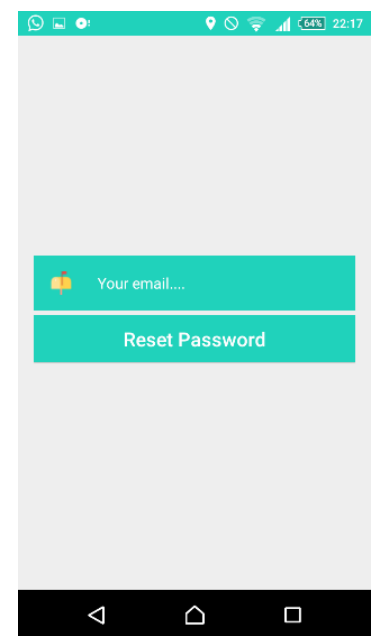

Gambar 4. Halaman lupa password pada aplikasi HelloCare

Gambar 4 merupakan tampilan forgot password pada aplikasi HelloCare. Ketika pengguna lupa dengan password yang telah didaftarkannya, maka pengguna tetap bisa mengakses aplikasi tersebut dengan memilih tombol forgot password. Setelah pengguna memilih tombol forgot password tersebut, pengguna diminta memasukkan e-mail yang telah didaftarkannya untuk bisa mendapatkan password yang baru.

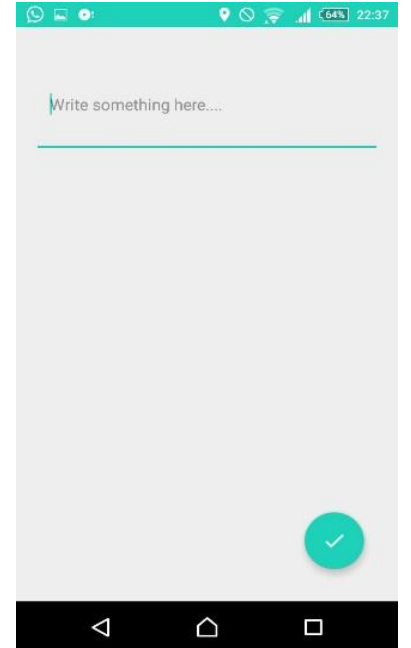

Gambar 5. Halaman update status pada aplikasi HelloCare

Pada Gambar 5 merupakan bagian dari tampilan aplikasi HelloCare pada menu New Post. Pengguna dapat meilhat seluruh aktifitas yang telah dibagikan oleh teman-teman pada aplikasi tersebut. Pengguna dapat membagikan pengalamannya dalam bentuk update status, upload photo, dan sharing file serta mencantumkan komentar mengenai post-an.

Gambar 6. Source code forgot password pada aplikasi HelloCare

Gambar 6 menggambarkan source code java pada bagian forgot password. Dalam hal tersebut jika pengguna telah menekan tombol reset password, maka program akan membaca $e$-mail pengguna

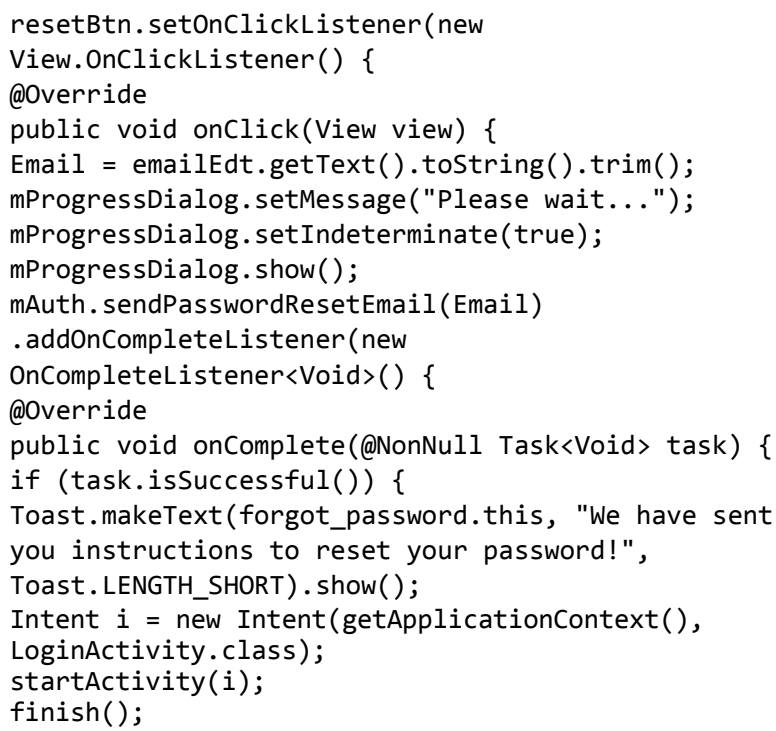

yang sudah dimasukkan sebelumnya. Kemudian akan tampil sebuah progress dialog agar pengguna menunggu proses pengiriman link pada $e$-mail. Jika $e$-mail sudah terkirim, maka pada tampilan aplikasi yang digunakan akan muncul toast atau notif yang bertuliskan "We have sent you instructions to reset 
your password!". Yang artinya password sudah bisa untuk diganti.

Gambar 7. Source code Upload File pada aplikasi HelloCare

Gambar 7 menggambarkan source code saat mendownload file. Jika masukkan dari pengguna bukan berbentuk image atau file, maka tidak ada gambar atau teks dalam bentuk link untuk mendownload file. Namun, jika yang diupload oleh pengguna yaitu gambar, atau format dalam bentuk .jpg, maka gambar dapat ditampilkan dan gambar bisa diakses dari link storage firebase dimana

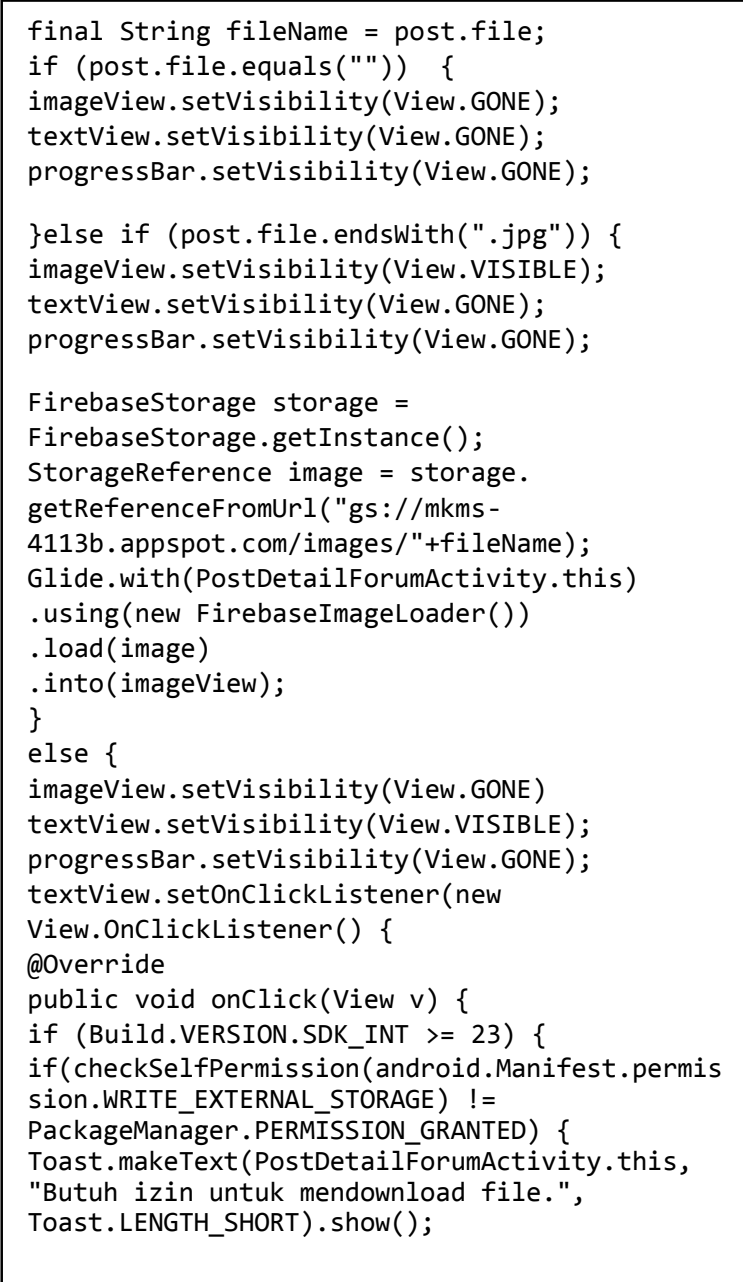

tempat penyimpanan seluruh data yang diunggah oleh pengguna. Selain itu, jika yang diupload oleh pengguna adalah bentuk file, maka akan tampil sebuah teks agar pengguna dapat mendownload file tersebut. Teks tersebut dapat diklik dan akan menampilkan teks berikutnya untuk bisa mendownload file. Kemudian setelah itu file dapat terbuka.

\section{Hasil dan Analisis}

Dalam pengujian aplikasi HelloCare terdapat dua pengujian yang dilakukan, yang pertama yaitu pengujian menggunakan prinsipprinsip System Usability Scale (SUS) dan yang kedua pengujian menggunakan prinsip-prinsip knowledge management. Pada pengujian pertama pada aplikasi mobile HelloCare dilakukan dengan memberikan kuesioner offline kepada responden untuk mengetahui kepuasan pengguna. Kemudian pengujian kedua dilakukan dengan memberikan kuesioner online kepada responden untuk mengetahui seberapa berfungsi aplikasi HelloCare terhadap pengembangan pengetahuan yang didapatkan. Kedua pengujian tersebut diberikan kepada 30 responden dengan karakteristik seorang dokter, perawat, mahasiswi koas, dan perawat yang sedang praktek kerja lapangan.

Secara keseluruhan aplikasi HelloCare memberikan fitur-fitur dengan fungsi yang efektif. Berdasarkan hasil pengujian menggunakan System Usability Scale, rata-rata nilai sebanyak $80,88 \%$, dengan persentase tertinggi yaitu sebanyak $84,66 \%$ terdapat pada fitur Daily Reminder yang sangat bermanfaat bagi pengguna untuk menjadwalkan kegiatannya sehari-hari. Selanjutnya, pada fitur profil pengguna mendapatkan persentase sebanyak $83,30 \%$. Dalam fitur ini pengguna merasa mudah untuk mengoperasikannya, serta informasi yang ditampilkan sudah cukup bermanfaat untuk memberitahu pengguna tentang dirinya. Selain itu itur Create Thread juga termasuk fitur yang memberi manfaat baik untuk user agar mereka bisa saling bertukar pikiran terkait ilmu yang dimiliki antar sesama tenaga kesehatan.

Pada fitur login, pengguna juga merasa sistem mudah untuk login dan memberi informasi yang jelas untuk bisa masuk pada aplikasi HelloCare. Selain itu juga pada bagian komentar saat user membagikan informasi tertentu, fungsi sistem sangat mudah digunakan dan informasi yang dimasukkan sangat bermanfaat. Pada fitur Wiki juga user merasa puas karena informasi yang ditampilkan lengkap dan sangat bermanfaat. Fitur-fitur tersebut mendapatkan peresentase sebanyak kurang lebih $82 \%$. Selain itu fitur-fitur seperti informasi yang ditampilkan pada fitur forum, kemudahan pada fungsi Wiki, kelengkapan informasi pada fitur Daily Activities dan juga informasi dan kemudahan pada fungsi update status mendapatkan persentase sebanyak kurang lebih $77,92 \%$. Pada pengujian kepuasan pengguna, persentase keseluruhan mencapai $96,16 \%$.

\section{Kesimpulan}

Pengembangan aplikasi HelloCare menggunakan metode scrum telah dilakukan. Aplikasi ini bertujuan untuk menfasilitasi 
knowledge sharing terhadap sesama tenaga kesehatan. Berdasarkan hasil pengujian System Usability Scale dapat disimpulkan bahwa aplikasi HelloCare memiliki tampilan yang menarik, komposisi warna yang sesuai, pengguna juga merasa senang pada saat menggunakan aplikasi sehingga mampu mencapai $100 \%$ tingkat kepuasan responden dalam menggunakan aplikasi tersebut.

\section{Daftar Pustaka}

Arisha, A. and Ragab, M. Knowledge management and measurement: a critical review. Journal of Knowledge Management, Vol. 17n Issue: 6

Chamsaria, N., 2014. Rancang Bangun Knowledge Management System Bagi Para Dokter Berbasis Web Serta Tinjauannya Menurut Agama Islam

Ilmawan, L. B, Azhari, S. N. Pendekatan Dokumentasi pada Agile Methods (n. d)

Kurniawati. S. (n.d.). Knowledge Management, Diakses dari ,

http://file.upi.edu/Direktori/FPEB/PRODI._E KONOMI_DAN_KOPERASI/SUSANTI_K URNIAWATI/MAKALAH/KNOWLEDGE _MANAGEMENT.pdf

Nonaka, et all., (1998). Building a Foundation for Knowledge Creation, California Management Review. , 40.

Rahmi, N. M, 2016. Pembangunan Sistem Manajemen Pengetahuan (Knowledge Management System) untuk Tenaga Kesehatan Serta Tinjauannya Menurut Agama Islam

Schwaber, K., (2013). web portal. The Scrum Guide

StatCounter, (2016). Statistik pengguna Smartphone di Indonesia: https://id.techinasia.com/android-operadominasi-smartphone-indonesia-2014. 